\title{
Risk assessment of freezing injury during overwintering of wheat in the northern boundary of the Winter Wheat Region in China
}

\author{
Jiahui Guo ${ }^{1}$, Xionghui Bai ${ }^{1}$, Weiping Shi ${ }^{1}$, Ruijie Li ${ }^{2}$, Xingyu Hao ${ }^{1}$, Hongfu Wang ${ }^{1}$, Zhiqiang Gao ${ }^{1}$, Jie Guo ${ }^{\text {Corresp., }}$, \\ Wen Lin ${ }^{\text {Corresp. } 1}$ \\ ${ }^{1}$ College of Agriculture, Shanxi Agricultural University, Taigu, Shanxi, China \\ 2 Maize Breeding Center, Zunhua Maize Breeding Institute of Hebei Province, Zunhua, Hebei, China \\ Corresponding Authors: Jie Guo, Wen Lin \\ Email address: nxgj1115326@sxau.edu.cn, slwr@sxau.edu.cn
}

Freezing injury is one of the main restriction factors for winter wheat production, especially in the northern part of the Winter Wheat Region in China. It is very important to assess the risk of winter wheat-freezing injury. However, most of the existing climate models are complex and cannot be widely used. In this study, Zunhua which is located in the northern boundary of Winter Wheat Region in China is selected as research region, based on the winter meteorological data of Zunhua from 1956 to 2016, seven freezing disaster-causing factors related to freezing injury were extracted to formulated the freezing injury index (FII) of wheat. Referring to the historical wheat-freezing injury in Zunhua and combining with the cold resistance identification data of the National Winter Wheat Variety Regional Test (NWWVRT), consistency between the FII and the actual freezing injury situation was tested. Furthermore, the occurrence law of freezing injury in Zunhua during the past 60 years was analyzed by Morlet wavelet analyze, and the risk of freezing injury in the short term was evaluated. Results showed that the FII can reflect the occurrence of winter wheat-freezing injury in Zunhua to a certain extent and had a significant linear correlation with the dead tiller rate of wheat $(P=0.014)$. The interannual variation of the $F / l$ in Zunhua also showed a significant downward trend $\left(R^{2}=0.7412\right)$. There are two cycles of freezing injury in 60 years, and it showed that there's still exist a high risk in the short term. This study provides reference information for the rational use of meteorological data for winter wheat-freezing injury risk assessment. 


\section{Introduction}

2 Among the four major grain crops in China, only winter wheat has a growth period that spans the

3 whole winter. Therefore, winter freezing injury is an important environmental stress that winter

4 wheat is facing. In China, the Northern Winter Wheat Region is one of the most important

5 wheat-producing areas, the wheat-planting area accounts for approximately $60 \%$ of the total

6 planting area, and yield accounts for approximately $80 \%$ of the total wheat yield in China (He et

7 al., 2011; Zhou et al., 2007). Before the mid-1980s, the harsh environment of freezing

8 temperatures and limitation of varieties caused winter wheat-freezing injury to be more serious

9 and frequent, and the decline in population density caused by freezing injury was the main

10 reason for wheat yield reduction (Zhu et al., 2014), with a decline of up to 30\%-60\% (Reynolds

11 et al., 2009). With global warming (Piao et al., 2010), some varieties with strong winter habit can

12 no longer meet the demand for low temperature to complete the vernalization process. Therefore,

13 the northern boundary of winter wheat planting in the northern region moved northward ( $\mathrm{Li}$ et al.,

14 2013), and the variety structure of the Northern Spring Wheat Region southern boundary

15 gradually transformed into the winter wheat. However, the frequency of extreme cold climate

16 has increased, which also increases the probability of large-scale freezing injury at the junction 17 area of winter and spring wheat (Chen et al., 2017).

18 Wheat-freezing injury occurs when the temperature is lower than $0^{\circ} \mathrm{C}$ (Ikkonen et al., 2020), 19 accompanied by various types of freezing injury, including the sudden drop of temperature in 20 early winter, the long cold in winter, the combination of drought and freezing, and freeze-thaw 21 in early spring (Zheng \& Qi, 1984). When occur to freezing injury, a large number of reactive 22 oxygen and abiotic free radicals accumulate in plants (Soltész et al., 2011; Kendall \& McKersie, 23 1989), that damage the cellular internal environment and membrane system, even cause the leaf 24 wilting and tillering death (Hassan et al., 2021). All of these factors result in wheat not smoothly 25 getting through winter.

26 Recently, freezing injury has become a hotspot in addition to drought (Barlow et al., 2015), 27 waterlogging (Herzog et al., 2016), and saline alkali (Kumar et al., 2015), and many researchers 28 have conducted in-depth studies on it (Frederiks et al., 2012; Koemel et al., 2004). For example, 29 Zhu et al. (2018) analyzed the relationship between multiple meteorological factors and the 30 actual occurrence of freezing injury in Henan province, China. They obtained specific 31 meteorological conditions for severe freezing injury and proposed that the complexity of the 32 severe freezing injury mechanism was not explained by simple temperature data. Zheng et al. 33 (2015) proposed that the absolute value of negative accumulated temperature during 34 overwintering periods could be used as an index to divide the degree of winter wheat-freezing 
35

36

37

38

39

40

41

42

43

44

45

46

47

48

49

50

51

52

53

54

55

56

57

58

59

60

61

62

63

64

\section{Materials \& methods}

\section{Overview of the research region}

67

68 zone. (Maiorano et al., 2017).

injury. Additionally, Bake et al. (2006) comprehensively considered the cold resistance ability of varieties and environmental factors, and established a wheat-freezing injury early warning system in Beijing using the decision tree method. This system described the cold resistance ability of seedlings, winter frostbite situation, and frost damage degree. Meng et al. (2019) comprehensively considered the influence of temperature, precipitation, and wind speed during the overwintering period, selected six freezing disaster-causing factors to establish winter wheatfreezing injury index equations for three subregions of the Northern Winter Wheat Region and conducted an overall assessment of wheat-freezing injury risk in this agroecological production

Many wheat physiological models have been successfully applied in the actual production of wheat-freezing injury simulation, including the Ceres-Wheat (Singh, Tripathy \& Chopra, 2008; Jamieson et al., 1998; Liu, Yao \& Jiang, 2021), WOFOST (Eitzinger et al., 2004), and FROST models (Fowler, Limin \& Ritchie, 1999; Bergjorda, Bonesmo \& Skjelvåg, 2008). These models explained the mechanism of wheat-freezing injury to a certain extent, which played an important role in early warning and post-disaster evaluation of freezing injury (Liu, Yao \& Jiang, 2021). However, the construction of these models lacks simplicity and operability. Additionally, these models are partial to theoretical calculation in the use of application as professionals should obtain data through complex software operations (Wolf et al., 1996). More importantly, data collection needs the help of many precision instruments, such as temperature and humidity sensors, where the accuracy of the instrument will greatly affect the accuracy of the data

In this study, we comprehensively considered the climatic factors related to freezing injury, such as the water condition before overwintering, the temperature during winter, negatively accumulated temperature, and precipitation. After that, we formulated a freezing injury index (FII) to represent the occurrence degree of wheat-freezing injury. The applicability of the FII was then verified using historical data on the description of the wheat-freezing injury and the cold resistance identification data on wheat. In addition, the occurrence of freezing injury in the short term was predicted. Our results provide a theoretical basis for making full use of agrometeorological data to assess the risk of freezing injury to guide winter wheat production.

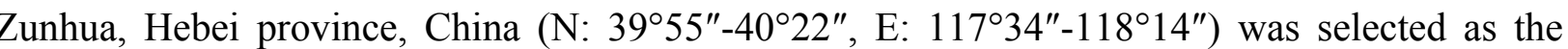
research region. It is located in the boundary of the Hebei province winter wheat-planting area,

Peer) reviewing PDF | (2021:06:62302:1:0:NEW 13 Aug 2021) 
69 as well as by a northern boundary of the Northern Winter Wheat Region (Fig. 1). Additionally, it 70 is the cold resistance identification test site of the NWWVRT in China. Therefore, it is of great 71 significance to study the prevalence of winter wheat-freezing injury in this region.

72

\section{Data sources of meteorological and freezing injury information}

74 The data of daily maximum temperature, minimum temperature, average temperature, and 75 precipitation used in this study were obtained from 1956 to 2016 from the surface weather 76 stations in the China Meteorological Data Network (http://data.cma.cn). Information on 77 historical winter wheat-freezing injury was also obtained from the China Meteorological Disaster 78 Yearbook: Hebei volume (Zang, 2008) and related research (Dai et al., 2010). The dead tiller rate data of wheat were obtained from the NWWVRT from 2007 to 2016.

80

\section{Formulation and test of the FII}

\section{Determination of the overwintering period}

83 Winter wheat will suffer from freezing injury when the temperature drops below $0^{\circ} \mathrm{C}$. Thus, the overwintering period is determined by the standard that the daily average temperature is lower than $0^{\circ} \mathrm{C}$ (Zhang et al., 2019). In this study, the starting and ending dates of the daily average temperature stably lower than $0^{\circ} \mathrm{C}$ were calculated using a five-day moving average method-the daily average temperature for five consecutive days is lower than $0{ }^{\circ} \mathrm{C}$ (Yao et al., 2011). Intervals define the overwintering period (Zheng et al., 2015).

\section{Selection of freezing disaster-causing factors}

According to meteorological data and actual climate conditions of Zunhua, seven climatic factors, including precipitation before overwintering, the extreme minimum temperature during overwintering periods, maximum-cooling range, maximum daily temperature difference, negatively accumulated temperature, average temperature, and total precipitation during overwintering periods, were selected as the freezing disaster-causing factors of winter after determining the overwintering period (Table 1). These factors include the water status before and during the overwintering period, as well as the intensity, duration, and cumulative effect of the low temperature, which can effectively reflect the mechanism of freezing injury to a certain extent.

\section{Formulation of the FII equation}


103 the range-standardized values of the seven selected freezing disaster-causing factors (Meng et al., 104 2019). Before that, a correlation test was conducted to determine whether these data were 105 suitable for principal component extraction (via IBM SPSS v.26.0). The data of the freezing 106 disaster-causing factors were standardized after the test. Additionally, positive and negative 107 indices are judged according to the influence of a certain index (i.e., freezing disaster-causing 108 factors) change on the occurrence degree of wheat-freezing injury. If the index value was larger 109 and the influence on the freezing injury degree was greater, it showed a positive index. However, 110 if the index value was larger and the influence on the freezing injury degree was smaller, it 111 indicated a negative index. The positive index is calculated using formula (1), whereas the 112 negative index is calculated using formula (2).

The positive and negative judgments of the freezing disaster-causing factor index and the choice of the range standardization formula are shown in Table S1.

Furthermore, the range-standardized values of seven disaster-causing factors were analyzed using PCA, and principal components whose eigenvalues $>1.0$ were extracted. The weight coefficient of each freezing disaster-causing factor was then calculated using the sum of the proportion of the corresponding eigenvalues of each principal component and its variance product to the total variance of the extracted principal components $a_{i}\left(a_{1} \sim a_{7}\right)$. Finally, the weighted summation of formula (3) is substituted to obtain the principal component synthesis expression, FII. The calculation formula of FII is as follows:

124

$$
F I I=\sum_{i=1}^{s} a_{i} x_{i},(3)
$$

where FII is the annual freezing injury index, $x_{i}$ is the range-standardized value of a freezing disaster-causing factor, and $a_{i}$ is the weight coefficient of the corresponding freezing disastercausing factor.

\section{Fit-test of FIl and freezing injury degree}

130 Existed studies (Fuller et al., 2007) mostly have used the dead plant rate (the ratio of the dead plant to the total plant) to determine the degree of wheat-freezing injury. However, this situation is limited to severe freezing injury. When freezing injury is mild, whole plant death rarely occurs, and it is the death of some tillers of the plant (Limin \& Fowler, 2006). Therefore, the ratio of dead tillers to total tillers was used as the index to judge the degree of freezing injury in this 
135 study. To explore the relationship between the FII and the actual freezing injury degree, FII and 136 data on the tiller death rate of Zunhua NWWVRT from 2007 to 2016 were used for univariate

137 linear regression analysis (via IBM SPSS v.26.0).

138

139

\section{Wavelet analysis}

140

Wavelet analysis can indicate the periodic characteristics of time series information in different timescales, and it is better to show the change trend and qualitatively predict the future development trend (Kumar \& Foufoula-Georgiou, 1993). In this study, the Morlet wavelet (Peng et al., 2013) was used to analyze the FII data from 1956 to 2016 (via MATLAB 2020b). As the time series data in this study were limited time series, the symmetry extension method was used to extend the two ends of the series to eliminate or reduce the possible "edge effect". The Morlet complex wavelet function in the wavelet toolbox of MATLAB was then used to transform the extended data sequence, calculate the real part of the wavelet coefficients, and draw the real part diagram of the wavelet coefficients. The wavelet toolbox was further used to calculate the wavelet variance and to draw the wavelet variance and main period wavelet coefficient diagrams.

150

\section{Results}

152 The starting and ending dates and the change trend of the overwintering period in 153 each year

154 The starting and ending dates of the daily average temperature stably lower than $0^{\circ} \mathrm{C}$ (i.e., the starting and ending dates of the overwintering period in each year) in each year were obtained from the five-day moving average method (Fig. 2). According to the change in the starting and ending dates of the overwintering period over the years, the starting dates were gradually delayed (Fig. 2A), and the fluctuation range was from the middle and late November to early December and was gradually smaller. These results indicate that the start date of the overwintering period was gradually stable in early December. Additionally, the end date was gradually advanced (Fig. 2B), and the fluctuation range was advanced from the middle and early March to the middle and late February, but the fluctuation range was large, indicating that the end date of overwintering was unstable.

\section{Formulation and verification of the FIl equation}

\section{Correlation between freezing disaster-causing factors}

Information on the seven freezing disaster-causing factors in the overwintering period of each 
168

169

170

171

172

\section{Formulation of the FIl equation}

174

175

176

177

178

179

180

181

182

183

184

185

186

187

188

189

190

191

192

193

194

195

196

197

198

199

200

201 severe freezing injury. calculated as follows:

$$
y=-34.826+65.511 x,(5)
$$

year was calculated, and a correlation test was conducted (Fig. 3). Results show that there was a certain correlation among disastrous factors, except for the "precipitation before overwintering". These results indicated that a comprehensive variable can be constructed by the PCA method to reflect the information contained in the seven freezing disaster-causing factors.

$\mathrm{KMO}$ and Bartlett sphericity test showed that the data were suitable for PCA $(\mathrm{KMO}=0.639, P=$ 1.18E-25). In total, two effective principal components were extracted, and the total variance interpretation rate was $62.85 \%$. The weight coefficient FII in formula (3) was calculated from the sum of the proportion of the product of the eigenvalue corresponding to the principal component and its variance to the total variance of the extracted principal component.

Eventually, it can be seen from formula (4) that when the more range-standardized value of freezing disaster-causing factors, the more FII value, indicated that the more risk probability of

$$
F I I=0.144 x_{1}+0.262 x_{2}+0.119 x_{3}+0.413 x_{4}+0.326 x_{5}+0.278 x_{6}+0.331 x_{7} .
$$

\section{Verification of $\boldsymbol{F l l}$ values and wheat-freezing injury}

The range-standardized values for seven freezing disaster-causing factors in each year were substituted into formula (4) to obtain FII values for each year (Fig. 4). Combined with the occurrence of wheat-freezing injury in history (Zang, 2008), our results showed that FII values were higher during the severe freezing injury year (the year indicated by the arrow in Fig. 4). These values better reflect the situation of historical freezing injury, which indicated that the FII can be used to reflect the actual situation of winter wheat-freezing injury.

On the basis of the cold resistance identification of the Zunhua NWWVRT, univariate linear regression was used to analyze the relationship between the dead tiller rate and FII values. Regression analysis showed that the dead tiller rate and $F I I$ value passed the 0.05 significance test $(P=0.014)$, indicating that a reliable functional relationship can be established between the two indicators. According to the histogram of the residual error of the regression analysis model used, the overall distribution of the residual error was normal. Combined with a P-P diagram, the regression model has a good fit (Fig. 5). The linear regression equation of univariate was

where $x$ and $y$ represent the FII index and dead tiller rate, respectively.

Regression analysis results also showed that the larger the FII value was, the higher the 
202 dead tiller rate was and the more severe the degree of freezing injury was. It showed that the FII

203 value was a good representation of the degree of freezing injury and had high applicability.

204

\section{Analysis on the change trend and causes of the FIl values}

206 As the FII values can reflect the degree of freezing injury, it is of practical significance to 207 analyze the change trend of $F I I$ values in 60 years. As the result shows, the interannual variation 208 range of the FII values in Zunhua is $0.485-1.566$ from 1956 to 2016, with the maximum value 209 from 1968 to 1969 and the minimum value from 2014 to 2015 (Fig. 4). From the results, the 210 amplitude of the FII between 1956 and 1986 was larger than 1987 to 2016, and there are many 211 peaks during this period, which indicated that wheat-freezing injury occurred frequently in this 212 period. By contrast, from 1987 to 2016, the amplitude of the $F I I$ was small, and the frequency of 213 freezing injury was less. Observed the change trend of the FII curve during this period, 19952141996 and 2009-2011 had the two largest peaks where severe freezing injury occurs. From 215 overall view, the interannual variation trend of the FII in Zunhua showed a significant downward 216 trend $\left(R^{2}=0.7412\right)$ in the 60-year period from 1956 to 2016 , but the interannual fluctuation 217 range within whole period was large, with a coefficient of variation value of $27.2 \%$. At the end 218 of the curve, the fluctuation range of the FII increased, which indicates that the risk probability 219 of freezing injury has also increased.

220

For the change of the overwintering period in 60 years, the delay in the starting time and

221 advance in the ending time of the overwintering period (Fig. 2) led to the shortening of the

222 overwintering period (Fig. 6A). The extreme minimum temperature (Fig. 6B), average

223 temperature (Fig. 6C), and negatively accumulated temperature (Fig. 6D) during the

224 overwintering period also showed an increasing trend. This result show that the gradual warming

225 of the overwintering environment of winter wheat, which is conducive to safe overwintering.

226 Correspondingly, the change in the FII over the years showed a decreasing trend (Fig. 4).

227 Although the climate was gradually warming in the general environment, the frequency of

228 extreme climate increased recently, and the risk of wheat-freezing injury increased.

229

\section{Wavelet analysis}

231 Three periods, including short (0-10a) ("a" means the timescale "year"), medium (11-20a), and 232 long periods (21-35a), were identified in the evolution process of the FII (Fig. 7A). The long 233 period (21-35a) spanned the whole timescale, showing obvious seasonal changes in abundantwithered-abundant, with peaks in 1963, 1985, and 2007, respectively. The periodicity of the 
236 10a) was more obvious than that of the medium period (11-20a). In the wavelet variance curve 237 (Fig. 7B), the fluctuation energy of the FII time series also has a clear peak on the timescale of 238 33a, which indicates that the periodic oscillation around 33a was the strongest. This was the first 239 main cycle of the variation. Similarly, a low peak value on the timescale of $4 \mathrm{a}$ was also observed, 240 which is the second main cycle of annual variation. Additionally, the average period of change 241 was approximately 40 years on the $33 \mathrm{a}$ timescale, and it has experienced approximately 1.5 242 abundant-withered periods (the red curve in Fig. 7C). On the 4a timescale, the average period of 243 change was approximately five years, which has experienced approximately 12 abundant-

244

\section{Discussion}

253

254

255

256

257

258

259

260

261

262

263

264

265

266

267

268

269 withered periods (the blue curve in Fig. 7C).

As a whole, the real part of the wavelet was not completely closed at the right end (Fig. 7C), which indicates that it was still in the period of high risk of freezing injury. Additionally, the right end value of the first principal period curve of the periodic wavelet coefficient graph did not drop below zero, and the second principal period was at its peak, which indicates that the fluctuation energy of the freezing injury probability was strong in a short term. This result also indicates that the risk of wheat-freezing injury probability was high.

\section{Occurrence and evolution of freezing injury and its climatic characteristics}

Because the FII is a better representation of the real freezing injury situation (Fig. 4, Fig. 5), the occurrence and evolution law of winter wheat-freezing injury in Zunhua in the past 60 years can be analyzed according to the change trend in FII. From the change in FII within 60 years, the freezing injury of winter wheat in the first 30 years showed the characteristics of heavy degree, high frequency, and large interannual fluctuation, indicating that the climate in winter before the mid-1980s was harsh and that climate change was unstable (Zhu et al., 2014). The low temperature and absolute value of the negatively accumulated temperature during the overwinter period were also large, and the frequency of extreme low temperature was high. These conditions were not conducive to winter wheat, which further led to a decrease in population density and yield reduction (Livingston \& Swinbank, 1962; Fowler et al., 1996).

After the mid-1980s, the occurrence degree and frequency of freezing injury decreased (Tao et al., 2006), which was proposed to be caused by global warming (Zhai et al., 1999). In this study, the delay of the starting date and the advance of the ending date of the winter wheat overwinter period in Zunhua for the past 60 years led to the shortening of overwinter time. The negatively accumulated temperature, average temperature, and extreme minimum temperature of the overwinter period also showed an increasing trend (Fig. 6), which further confirmed the 
270 inference that climate warming reduced the risk of wheat-freezing injury.

271 Since the beginning of the 21st century, climate instability has increased (Tian et al., 2016).

272 Additionally, extreme climate events occurred frequently (Hänninen, 2006), and the probability

273 of winter wheat-freezing injury increased (Fig. 4). Our results found that the occurrence of

274 freezing injury in Zunhua over the past 60 years showed a periodic change, and the small period

275 was nested in the large period. At present, FII curve is at the end of a long period-positive peak

276 and the top of the short period-positive peak (Fig. 7C), indicating that the probability of wheat

277 frost damage in this area in the future will be relatively high. Therefore, to avoid severe freezing

278 injury of winter wheat, it is necessary to select wheat varieties with strong cold resistance in

279 future production processes, which can greatly reduce the impact of periodic freezing injury on

280 grain production.

281

282 Guidance of risk assessment of freezing injury to agricultural production

283 Our results showed that the probability of freezing injury in Zunhua was high in the short term

284 (Fig. 7C). On the basis of these results, the following problems in the production process should

285 be paid attention to: (1) the climate in the edge area of the original planting strong winter wheat 286 cannot meet the needs for wheat complete the vernalization process because of the gradual 287 warming of the climate. Previous studies have shown that the wheat variety structure in northern 288 boundary of Winter Wheat Region in China was gradually changing from a strong winter to 289 winter or semi-winter (Zheng, Ge \& Hao, 2002; Wang et al., 2013), which will increase the risk 290 probability of seedlings having freezing injury when they encounter extreme low temperature 291 weather (Paulsen \& Heyne, 1962). Therefore, growers should try selecting varieties with 292 stronger winter characters to reduce the adverse effects caused by climate change. (2) Owing to 293 the delay in the starting date of the wheat-overwintering period (Fig. 2A), the sowing time 294 should be appropriately late according to the actual climate conditions to prevent the vigorous 295 growth of seedlings before overwintering (Sadras \& Monzon, 2006). Simultaneously, irrigation 296 should be timely and sufficient before winter to avoid freezing injury caused by drought (Fischer, 297 1985). When breeding new winter wheat varieties, cold resistance should also be screened 298 (Zheng et al., 2015).

299

300 Suggestion on identification of cold resistance of varieties

301 Owing to global warming, cold resistance identification of new varieties in a field will result in a 302 situation where the dead plant and dead tiller rate of all varieties are zero (Wang et al., 2008). 303 Here, it was impossible to make an objective evaluation on the cold resistance of all varieties. 
304 Therefore, to fully reflect on the cold resistance of various varieties, the occurrence probability 305 of freezing injury can be improved by the following ways: (1) sowing all tested varieties in 306 advance to form exuberant seedlings before overwintering, which can increase the probability of 307 freezing injury of seedlings, or decrease planting density, which will increase the probability of

308

309

310

311

312

313

314

315

316

317

318

319

320

321

322

323

324

325

326

327

328

329

330

331

332

333

334

335

336

337

freezing injury (Fowler \& Limin, 2004). (2) Due to the north boundary of Winter Wheat Region is constantly moving north, the area with higher latitudes and worse wintering environment can also be added as a new cold resistance identification test point to fully reflect the cold resistance ability of various varieties(Chen et al., 2011; Yang, Liu \& Chen, 2011).

\section{Deficiency and suggestion of establishing the FIl equation}

The occurrence of winter wheat-freezing injury is an extremely complex process (Craufurd \& Wheeler, 2009). The seven freezing disaster-causing factors selected in this study for formulating a FII equation cover effective information such as the water condition before overwintering, the intensity, duration, and cumulative effect of low temperature, as well as the effective precipitation during overwintering. The FII can reflect the occurrence degree of winter wheatfreezing injury through the test. Our results showed that, the higher the FII value is, the more severe the freezing injury would be. In addition to the selected factors causing freezing injury, the occurrence of freezing injury is affected by wheat genetic factors (Yan et al., 2004; Fu et al., 2005), duration and thickness of snow cover (Yoshida et al., 2010), duration and speed of wind (Porter \& Gawith, 1999), and cultivation management methods (Hassan et al., 2021). For example, during the overwintering period of 2012-2013, wheat seedlings were covered with snow for approximately one month, which effectively protects seedlings; hence, the freezing injury degree of seedlings was less, but the FII value was higher. Thus, more meteorological factors related to wheat-freezing injury can be included in the formulation of a FII. However, it should also be noted that the increase in data collection make this model more complex, which is not conducive to the operation of users.

Additionally, soil moisture condition has a great impact on wheat overwintering as drought aggravates the occurrence of freezing injury (AI-Issawi et al., 2013). The content of soil moisture during overwintering directly affects the occurrence probability of wheat-freezing injury (Alireza et al., 2021). We speculate that taking soil moisture content as the water condition factor of FII equation probably achieve more accurate prediction effect. In conclusion, the establishment of the $F I I$ equation needs to be further improved.

\section{Conclusions}


338 Seven freezing disaster-causing factors were chosen to formulated FII in Zunhua from 1956 to 339 2016. The results show that FII can reflect the freezing injury situation in Zunhua over the years.

340 According to the analysis of the climatic factors during the overwintering period, the delay in the

341 start date and the advance of the end date led to shortening of the overwintering period.

342 Additionally, the climate conditions were gradually mild, and the occurrence degree of winter

343 wheat-freezing injury showed a significant downward trend $\left(R^{2}=0.7412\right)$. Wavelet analysis

344 shows that the change of FII has clear periodicity in the whole timescale. And it can be predicted

345 that Zunhua is still in a high-risk period of freezing injury.

346

347 Acknowledgments

348 We gratefully acknowledge help from Prof. Robert A McIntosh, University of Sydney, with 349 English editing.

350

351 Additional Information and Declarations

352 Funding

353 This work was supported by grants from the National Key R\&D Program of China 354 (2017YFD0101000), National Natural Science Foundation of China (31901541), Natural 355 Science Foundation of Shanxi Province (201901D211361). The funders had no role in study 356 design, data collection and analysis, decision to publish, or preparation of the manuscript.

357 Grant Disclosures

358 The following grant information was disclosed by the authors:

359 National Key R\&D Program of China: 2017YFD0101000.

360 National Natural Science Foundation of China: 31901541.

361 Natural Science Foundation of Shanxi Province: 201901D211361.

362 Competing Interests

363 The authors declare there are no competing interests.

364 Author Contributions

365 Jiahui Guo conceived and analyzed the data, prepared figures and/or tables, authored or reviewed 366 drafts of the paper, approved the final draft.

367 Xionghui Bai analyzed the data, prepared figures and/or tables, authored or reviewed drafts of 368 the paper, and approved the final draft.

369 Ruijie Li, Weiping Shi and Xingyu Hao collected and analyzed the data, approved the final draft.

370 Zhiqiang Gao and Hongfu Wang contributed analysis tools and analyzed the data, authored or 371 reviewed drafts of the paper, approved the final draft. 
372 Jie Guo conceived and analyzed the data, authored or reviewed drafts of the paper, approved the 373 final draft.

374 Wen Lin conceived and analyzed the data, authored or reviewed drafts of the paper, approved the 375 final draft.

376

377 References

378 Alireza H, Mehdi R, Ebrahim ID, Ahmad N, Bhagirath SH. 2021. Regeneration capacity 379

Bergjorda AK, Bonesmo H, Skjelvåg AO. 2008. Modelling the course of frost tolerance in

Barlow KM, Christy BP, O’Leary GJ, Riffkin PA, Nuttall JG. 2015. Simulating the impact of extreme heat and frost events on wheat crop production: A review. Field Crops Research 171:109-119

DOI: $10.1016 /$ j.fcr.2014.11.010 winter wheat I . Model development. European Journal of Agronomy 28: 321-330 DOI: $10.1016 / j . e j a .2007 .10 .002$

Chen C, Baethgen WE, Wang EL, Yu Q. 2011. Characterizing spatial and temporal variability 
399

400

401

402

403

404

405

406

407

408

409

410

411

412

413

414

415

416

417

418

419

420

421

422

423

424

of crop yield caused by climate and irrigation in the North China Plain. Theoretical and Applied Genetics 106(3-4): 365-381

DOI: $10.1007 / \mathrm{s} 00704-011-0440-\mathrm{x}$

Chen Y, Zhang Z, Tao FL, Wang P, Wei X. 2017. Spatio-temporal patterns of winter wheat yield potential and yield gap during the past three decades in North China. Field Crops Research 206: 11-20

DOI: $10.1016 / j . f c r .2017 .02 .012$

Craufurd PQ, Wheeler TR. 2009. Climate change and the flowering time of annual crops. Journal of Experimental Botany 60(9): 2529-2539

DOI: $10.1093 / \mathrm{jxb} / \mathrm{erp} 196$

Dai LQ, Li CQ, Yao SR, Zhang WZ. 2010. Variation analysis of freezing injury on winter wheat under climate warming in Hebei province. Chinese Journal of Agrometeorolgy 31: $467-471$

DOI: $10.3969 /$ j.issn.1000-6362.2010.03.027

Eitzinger J, Trnka M, HöSch J, Žalud Z, Dubrovský M. 2004. Comparison of CERES, WOFOST and SWAP models in simulating soil water content during growing season under different soil conditions. Ecological Modelling 171(3): 223-246

DOI: $10.1016 /$ j.ecolmodel.2003.08.012

Fischer RA. 1985. Number of kernels in wheat crops and the influence of solar radiation and temperature. Journal of Agricultural Science 105(2): 447-461

DOI: $10.1017 / \mathrm{S} 0021859600056495$

Fowler DB, Limin AE. 2004. Interactions among factors regulating phenological development and acclimation rate determine low-temperature tolerance in wheat. Annals of Botany 94(5): 717-724

DOI: $10.1093 / \mathrm{aob} / \mathrm{mch} 196$

Fowler DB, Limin AE, Ritchie JT. 1999. Low-temperature tolerance in cereals: model and 
425

426

427

428

429

430

431

432

433

434

435

436

437

438

439

440

441

442

443

444

445

446

447

448

449

450

genetic interpretation. Crop Science 39: 626-633

DOI: 10.2135/cropsci1999.0011183X003900020002x

Fowler DB, Limin AE, Wang SY, Ward RW. 1996. Relationship between low-temperature tolerance and vernalization response in wheat and rye. Canadian Journal of Plant Science 76(1): $37-42$

DOI: $10.4141 /$ cjps96-007

Frederiks TM, Christopher JT, Harvey GL, Sutherland MW, Borrell AK. 2012. Current and emerging screening methods to identify post-head-emergence frost adaptation in wheat and barley. Journal of Experimental Botany 63(15): 5405-5416

DOI: $10.1093 / \mathrm{jxb} / \mathrm{ers} 215$

Fu DL, Szúcs P, Yan LL, Helguera M, Skinner JS, Von Zitzewitz J, Hayes PM, Dubcovsky J. 2005. Large deletions within the first intron in $V R N-1$ are associated with spring growth habit in barley and wheat. Molecular Genetics and Genomics 273: 54-65

DOI: $10.1007 / \mathrm{s} 00438-004-1095-4$

Fuller MP, Fuller AM, Kaniouras S, Christophers J, Fredericks T. 2007. The freezing characteristics of wheat at ear emergence. European Journal of Agronomy 26(4): 435-441 DOI: 10.1016/j.eja.2007.01.001

Hassan MA, Chen X, Farooq M, Muhammad N, Zhang Y, Xu H, Ke YY, Bruno AK, Zhang LL, Li JC. 2021. Cold stress in wheat: Plant acclimation responses and management strategies. Frontiers in Plant Science 12: 676884

DOI: $10.3389 /$ fpls.2021.676884

Hänninen H. 1991. Does climatic warming increase the risk of frost damage in northern trees? Plant Cell and Environment 14(5): 449-454

DOI: 10.1111/j.1365-3040.1991.tb01514.x

He ZH, Xia XC, Chen XM, Zhuang QS. 2011. Progress of Wheat Breeding in China and the Future Perspective. Acta Agronomica Sinica 37(02): 202-215 
DOI:10.3724/SP.J.1006.2011.00202

452 Herzog M, Striker GG, Colmer TD, Pedersen O. 2016. Mechanisms of waterlogging 453 454 tolerance in wheat: a review of root and shoot physiology. Plant Cell and Environment 39(5): 1068-1086

455

DOI: $10.1111 /$ pce. 12676

456 Ikkonen EN, Shibaeva TG, Sherudilo EG, Titov AF. 2020. Response of winter wheat 457 seedlings respiration to long-term cold exposure and short-term daily temperature drops. 458 459 Russian Journal of Plant Physiology 67(3): 538-544 DOI: $10.1134 / \mathrm{S} 1021443720020065$

461

462

463

464

465

466

467

468

469

470

471

472

473

474

475

476

Jamieson PD, Porter JR, Goudriaan J, Ritchie JT, van Keulen H, Stol W. 1998. A comparison of the models AFRCWHEAT2, CERES-Wheat, Sirius, SUCROS2 and SWHEAT with measurements from wheat grown under drought. Field Crops Research 55(1): $23-44$

DOI: 10.1016/S0378-4290(97)00060-9

Kendall EJ, Mckersie BD. 1989. Free radical and freezing injury to cell membranes of winter wheat. Physiologia Plantarum 76(1): 86-94

DOI: $10.1111 / \mathrm{j} .1399-3054.1989 . t b 05457 . x$

Koemel JE Jr, Guenzi AC, Anderson JA, Smith EL. 2004. Cold hardiness of wheat nearisogenic lines differing in vernalization alleles. Theoretical and Applied Genetics 109: $839-846$

DOI: $10.1007 / \mathrm{s} 00122-004-1686-9$

Kumar P, Foufoula-Georgiou E. 1993. A multicomponent decomposition of spatial rainfall fields: 1. Segregation of large-and small-scale features using wavelet transforms. Water Resources Research 29(8): 2515-2532

DOI: $10.1029 / 93 \mathrm{WR} 00548$

Kumar P, Sarangi A, Singh DK, Parihar SS, Sahoo RN. 2015. Simulation of salt dynamics in 
477

478

479

480

481

482

483

484

485

486

487

488

489

490

491

492

493

494

495

496

497

498

499

500

501

502

the root zone and yield of wheat crop under irrigated saline regimes using SWAP model. Agricultural Water Management 148(148): $72-83$

Li KN, Yang XG, Mu CY, Xu HJ, Chen F. 2013. The possible effects of global warming on cropping systems in China VIII: The effects of climate change on planting boundaries of different winte-spring varieties of winter wheat in China. Scientia Agricultura Sinica 46(08): 1583-1594

DOI: $10.3864 /$ j.issn.0578-1752.2013.08.007

Limin AE, Fowler DB. 2006. Low-temperature tolerance and genetic potential in wheat (Triticum aestivum L.): response to photoperiod, vernalization, and plant development. Planta 224: 360-366

DOI: $10.1007 / \mathrm{s} 00425-006-0219-\mathrm{y}$

Liu JC, Yao WB, Jiang MJ. 2021. Risk assessment of possible impacts of climate change and irrigation on wheat yield and quality with a modified CERES-Wheat model. Journal of Water and Climate Change jwc2021248

DOI: $10.2166 /$ wcc. 2021.248

Livingston JE, Swinbank JC. 1962. Some factors influencing the injury to winter wheat heads by low temperatures. Agronomy Journal 42(3): 153-157

DOI: 10.2134/agronj1950.00021962004200030006x

Maiorano A, Martre P, Asseng S, Ewertc F, Müllerd C, Röttere RP, Ruane AC, Semenov MA, Wallach D, Wang EL, Alderman PD, Kassieb BT, Biernath C, Basso B, Cammarano D, Challinor AJ, Doltra J, Dumont B, Rezaei EE, Gayler S, Kersebaum KC, Kimball BA, Koehler AK, Liu B, O’Leary GJ, Olesen JE, Ottman MJ, Priesack E, Reynolds M, Stratonovitch P, Streck T, Thorburn PJ, Waha K, Wall GW, White JW, Zhao ZG, Zhu Y. 2017. Crop model improvement reduces the uncertainty of the response to temperature of multi-model ensembles. Field Crops Research 202:5-20

DOI: $10.1016 /$ j.fcr.2016.05.001 
DOI: 10.1016/j.agwat.2014.09.014

504 Meng FY, Feng LP, Zhang FY, Zhang Y, Wu L, Wang CL, Yan JT, Peng MX, Mo ZH, Yu 505 WD. 2019. Temporal and spatial variations of winter wheat freezing injury in northern

506 winter wheat region. Acta Agronomica Sinica 45(10): 1576-1585

507 DOI: $10.3724 /$ SP.J.1006.2019.81076

508

509

510

511

512

513

514

515

516

517

518

519

520

521

522

523

524

525

526

527

528 Agronomy Journal 75(4): 705-707

DOI: 10.2134/agronj1983.00021962007500040031x

Peng J, Shen H, He SW, Wu JS. 2013. Soil moisture retrieving using hyperspectral data with the application of wavelet analysis. Environmental Earth Sciences 69: 279-288 DOI: $10.1007 / \mathrm{s} 12665-012-1955-\mathrm{x}$

Piao SL, Ciais P, Huang Y, Shen ZH, Peng SS, Li JS, Zhou LP, Liu HY, Ma YC, Ding YH, Friedingstein P, Liu CZ, Tan K, Yu YQ, Zhang TY, Fang JY. 2010. The impacts of climate change on water resources and agriculture in China. Nature 467(7311): 43-51 DOI: $10.1038 /$ nature09364

Porter JR, Gawith M. 1999. Temperatures and the growth and development of wheat: a review. European Journal of Agronomy 10(1): 23-36

DOI: $10.1016 / \mathrm{S} 1161-0301(98) 00047-1$

Reynolds M, Foulkes MJ, Slafer GA, Berry P, Parry MAJ, Snape JW, Angus WJ. 2009. Raising yield potential in wheat. Journal of Experimental Botany 60: 1899-1918 DOI: $10.1093 / \mathrm{jxb} / \mathrm{erp} 016$

Sadras VO, Monzon JP. 2006. Modelled wheat phenology captures rising temperature trends: Shortened time to flowering and maturity in Australia and Argentina. Field Crops Research 99(2-3): 136-146

DOI: $10.1016 /$ j.fcr.2006.04.003

Singh AK, Tripathy R, Chopra UK. 2008. Evaluation of CERES-Wheat and CropSyst models 
529

530

531

532

533

534

535

536

537

538

539

540

541

542

543

544

545

546

547

548

549

550

551

552

553

554

for water-nitrogen interactions in wheat crop. Agricultural Water Management 95(7): $776-786$

DOI: 10.1016/j.agwat.2008.02.006

Soltész A, Tímár I, Vashegyi I, Tóth B, Kellős T, Szalai G, Vágújfalvi A, Kocsy G, Galiba G. 2011. Redox changes during cold acclimation affect freezing tolerance but not the vegetative/reproductive transition of the shoot apex in wheat. Plant Biology 13: 757-766 DOI: $10.1111 / j .1438-8677.2010 .00429 . x$

Tao FL, Yokozawa M, Xu YL, Hayashi Y, Zhang Z. 2006. Climate changes and trends in phenology and yields of field crops in China, 1981-2000. Agricultural and Forest Meteorology 138(1-4): 82-92

DOI: 10.1016/j.agrformet.2006.03.014

Tian JY, Liu J, Wang JH, Li CZ, Nie HJ, Yu FL. 2016. Trend analysis of temperature and precipitation extremes in major grain producing area of China: Trends of climate extremes in major grain producing area of China. International Journal of Climatology 37(2): $672-687$

DOI: $10.1002 /$ joc. 4732

Wang HL, Gan YT, Wang RY, Niu JY, Zhao H, Yang QG, Li GC. 2008. Phenological trends in winter wheat and spring cotton in response to climate changes in northwest China. Agricultural and Forest Meteorology 148(8-9): 1242-1251

DOI: 10.1016/j.agrformet.2008.03.003

Wang J, Wang EL, Feng LP, Yin H, Yu WD. 2013. Phenological trends of winter wheat in response to varietal and temperature changes in the North China Plain. Field Crops Research 144(6): 135-144

DOI: $10.1016 /$ j.fcr.2012.12.020

Wolf J, Evans LG, Semenov MA, Eckersten H, Iglesias A. 1996. Comparison of wheat simulation models under climate change. I. Model calibration and sensitivity analyses. 
555

556

557

558

559

560

561

562

563

564

565

566

567

568

569

570

571

572

573

574

575

576

577

578

579

580

Climate Research 7(3): 253-270

DOI: $10.3354 / \mathrm{cr} 007253$

Yan L, Helguera M, Kato K, Fukuyama S, Sherman J, Dubcovsky J. 2004. Allelic variation at the VRN-1 promoter region in polyploidy wheat. Theoretial and Applied Genetics 109: 1677-1686

DOI: $10.1007 / \mathrm{s} 00122-004-1796-4$

Yang XG, Liu ZJ, Chen F. 2011. The possible effects of global warming on cropping systems in China VI. Possible effects of future climate change on northern Limits of cropping system in China. Scientia Agricultura Sinica 44(08): 1562-1570

DOI: CNKI: SUN: ZNYK.0.2011-08-005

Yao YP, Su GL, Luo WH, Dai JF. 2011. A photo-thermal resources based system for greenhouse climate zonation and energy consumption estimation in China. Scientia Agricultura Sinica 44(05): 898-908

DOI: $10.3864 / \mathrm{j}$. issn.0578-1752.2011.05.005

Yoshida M, Abe J, Moriyama M, Kuwabara T. 1998. Carbohydrate levels among winter wheat cultivars varying in freezing tolerance and snow mold resistance during autumn and winter. Physiologia Plantarum 103(1): 8-16

DOI: $10.1034 / \mathrm{j} .1399-3054.1998 .1030102 . \mathrm{x}$

Zang JS. 2008. China meteorological disaster yearbook: Hebei volume. Beijing: China Meteorological Press

Zhai PM, Sun AJ, Ren FM, Liu XN, Gao B, Zhang Q. 1999. Changes of climate extremes in China. Climate Change 42(1): 203-218

DOI: $10.1007 / 978-94-015-9265-9 \_13$

Zhang Y, Hu Q, He HY, Pan XB, Ma XQ, Huang BX, Wang J. 2019. Correspondence and shifting analysis for the winter wheat growing period before winter and solar terms in the north China plain under climate change background. Chinese Journal of Agrometeorolgy 
581

582

583

584

585

586

587

588

589

590

591

592

593

594

595

596

597

598

599

600

601

602

603

604

605

606

40(07): 411-421

DOI: $10.3969 /$ j.issn. 1000-6362.2019.07.001

Zheng BY, Chapman SC, Christopher JT, Frederiks TM, Chenu K. 2015. Frost trends and their estimated impact on yield in the Australian wheatbelt. Journal of Experimental Botany 66(12): 3611-3623

DOI: $10.1093 / \mathrm{jxb} / \mathrm{erv} 163$

Zheng DX, Yang XG, Zhao J, Mu CY, Gong Y. 2015. Spatial and temporal patterns of freezing injury during winter in Huang-Huai Winter Wheat Area under climate change. Acta Ecologica Sinica 35: 4338-4346

DOI: $10.5846 / \mathrm{stxb} 201406161251$

Zheng J, Ge Q, Hao Z. 2002. Impacts of climate warming on plants phenophases in China for the last 40 years. Chinese Science Bulletin 47(021): 1826-1831

DOI: $10.1360 / 02$ tb9399

Zheng W, Qi HN. 1984. Investigation on the ecological types of freezing injury to winter wheat in northwest China. Acta Agronomica Sinica 10(01): 35-40

Zhou Y, He ZH, Sui XX, Xia XC, Zhang XK, Zhang GS. 2007. Genetic improvement of grain yield and associated traits in the northern China winter wheat region from 1960 to 2000 . Crop Science 47: 245-253

DOI: $10.2135 /$ cropsci2006.03.0175

Zhu J, Pearce S, Burke A, See DR, Skinner DZ, Dubcovsky J, Garland-Campbell K. 2014. Copy number and haplotype variation at the VRN-A1 and central FR-A2 loci are associated with frost tolerance in hexaploid wheat. Theoretical and Applied Genetics 127: 1183-1197

DOI: $10.1007 / \mathrm{s} 00122-014-2290-2$

Zhu HH, Wu YF, Song JQ, Du KM. 2018. Analysis to late frost damage for winter wheat based on meteorological factors-taking Henan province as an example. Chinese Journal 
607 of Agrometeorolgy 39: 59-68

608 DOI: $10.3969 /$ j.issn. 1000-6362.2018.01.007 
Figure 1

Geographical coordinates of Zunhua and its location in the Northern Winter Wheat Region in China.

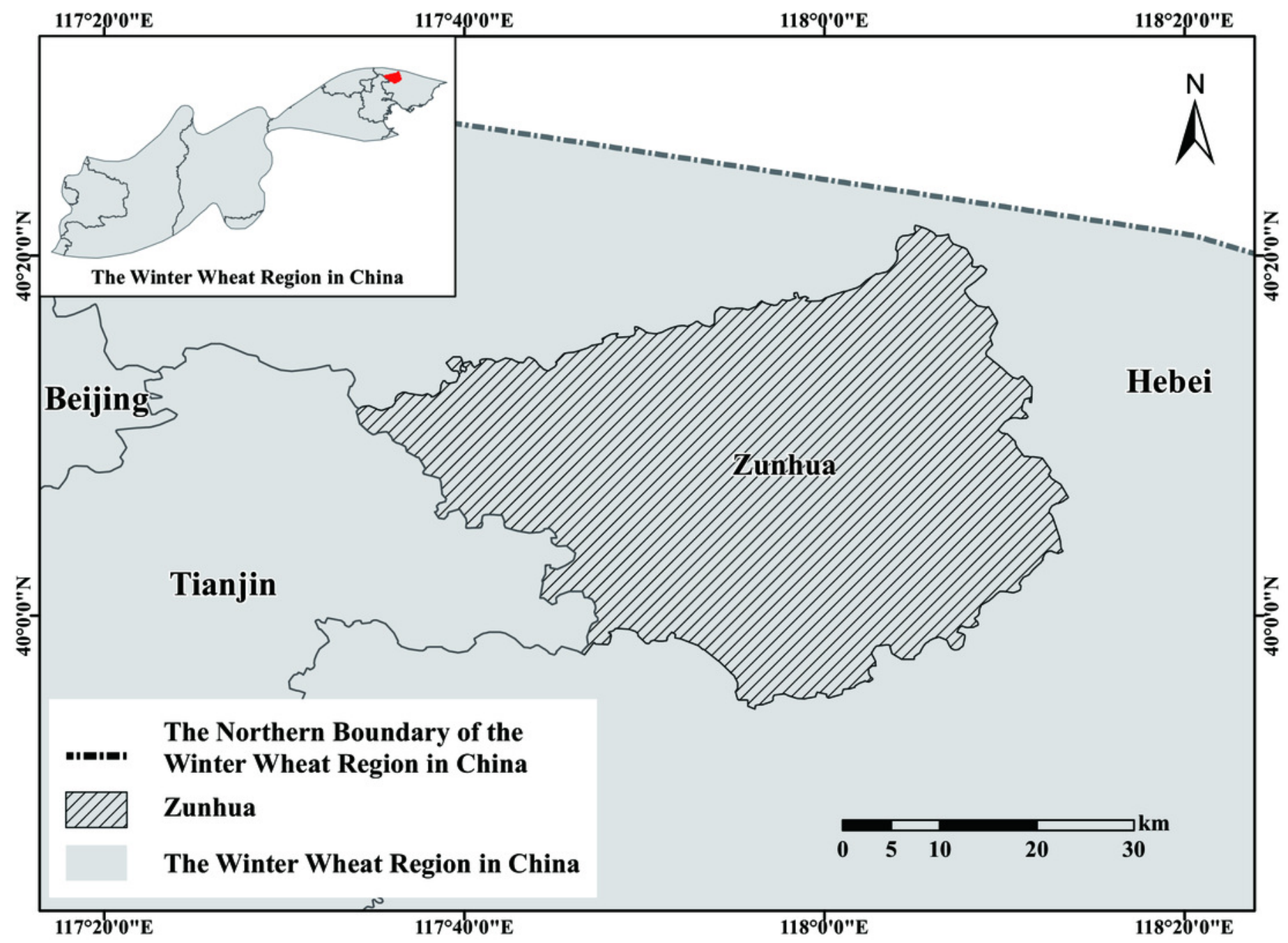


Figure 2

The starting and ending dates of the overwintering period.

(A) The starting date of the overwintering period. (B) The ending date of the overwintering period.
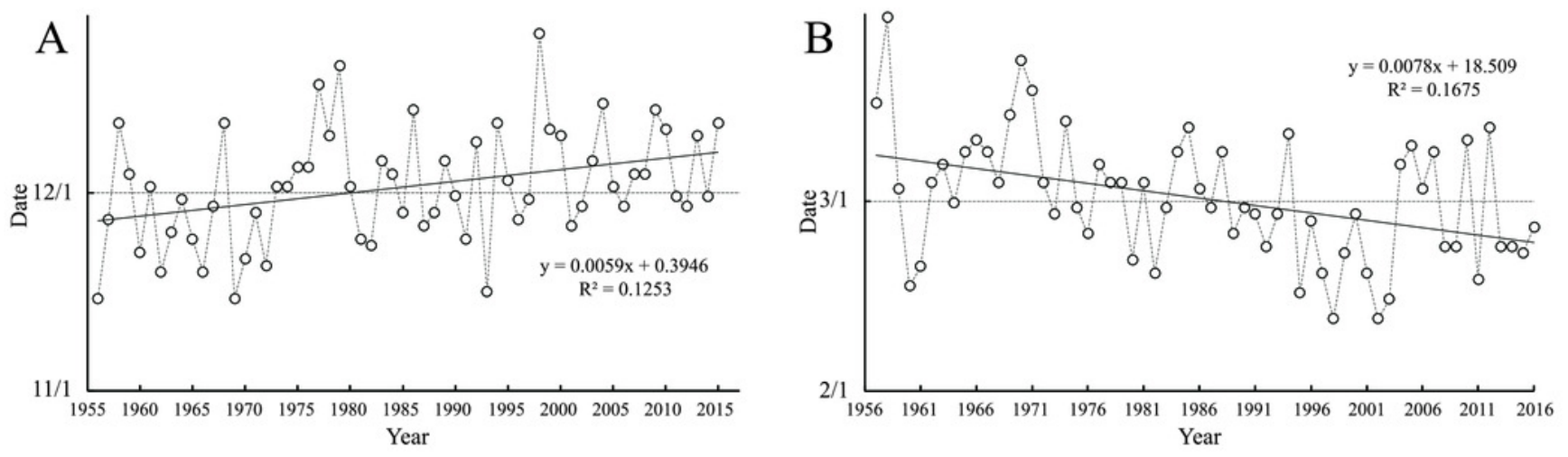


\section{Figure 3}

Correlation test of freezing disaster-causing factors.

I: Precipitation before overwintering; II: extreme minimum temperature during overwintering periods; III: maximum-cooling range during overwintering periods; IV: maximum daily temperature differences during overwintering periods; V: negatively accumulated temperature during overwintering periods; VI: average temperature during overwintering periods; VII: total precipitation during overwintering periods. * indicates a significant correlation at the 0.05 level, and ** indicates a significant correlation at the 0.01 level.

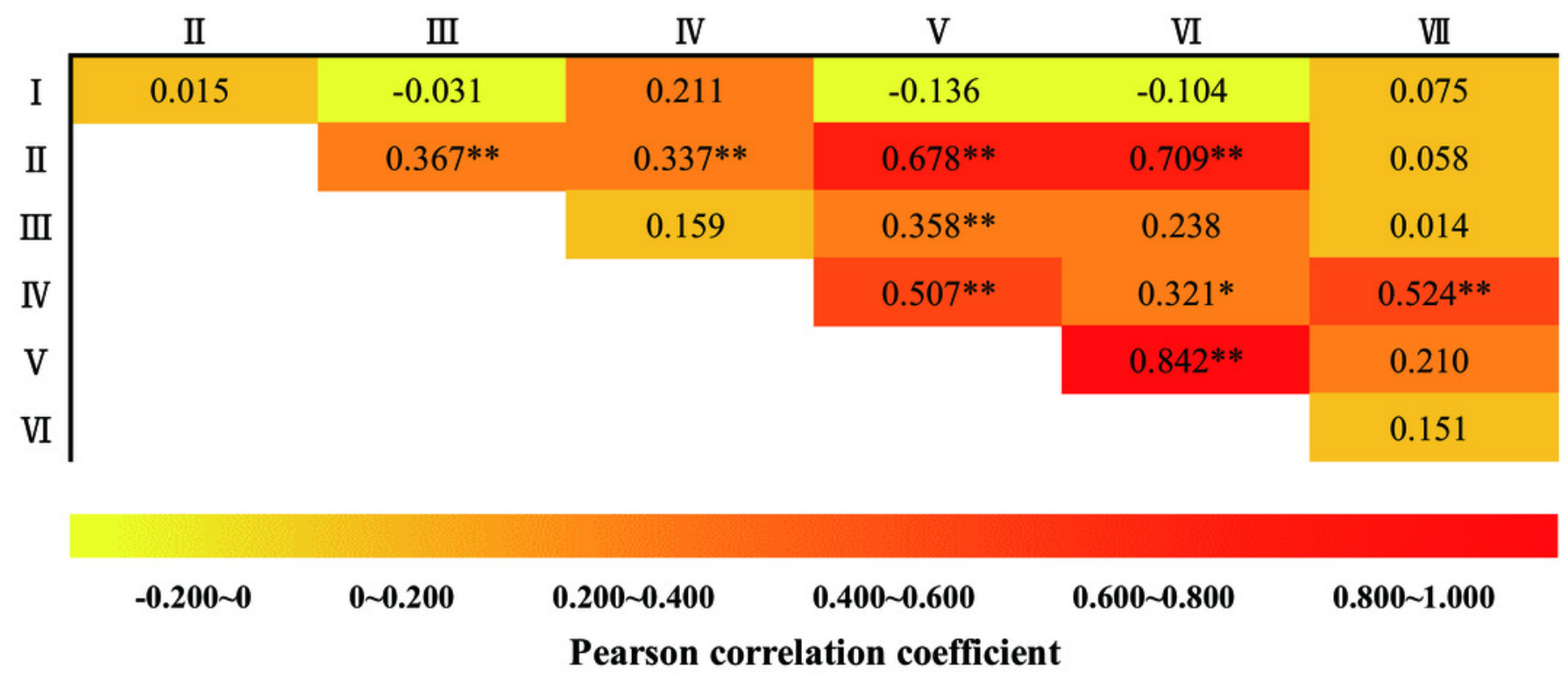


Figure 4

FIl value and changes in Zunhua from 1956 to 2016.

Red arrow represents the year in which the frost damage occurred in the historical record.

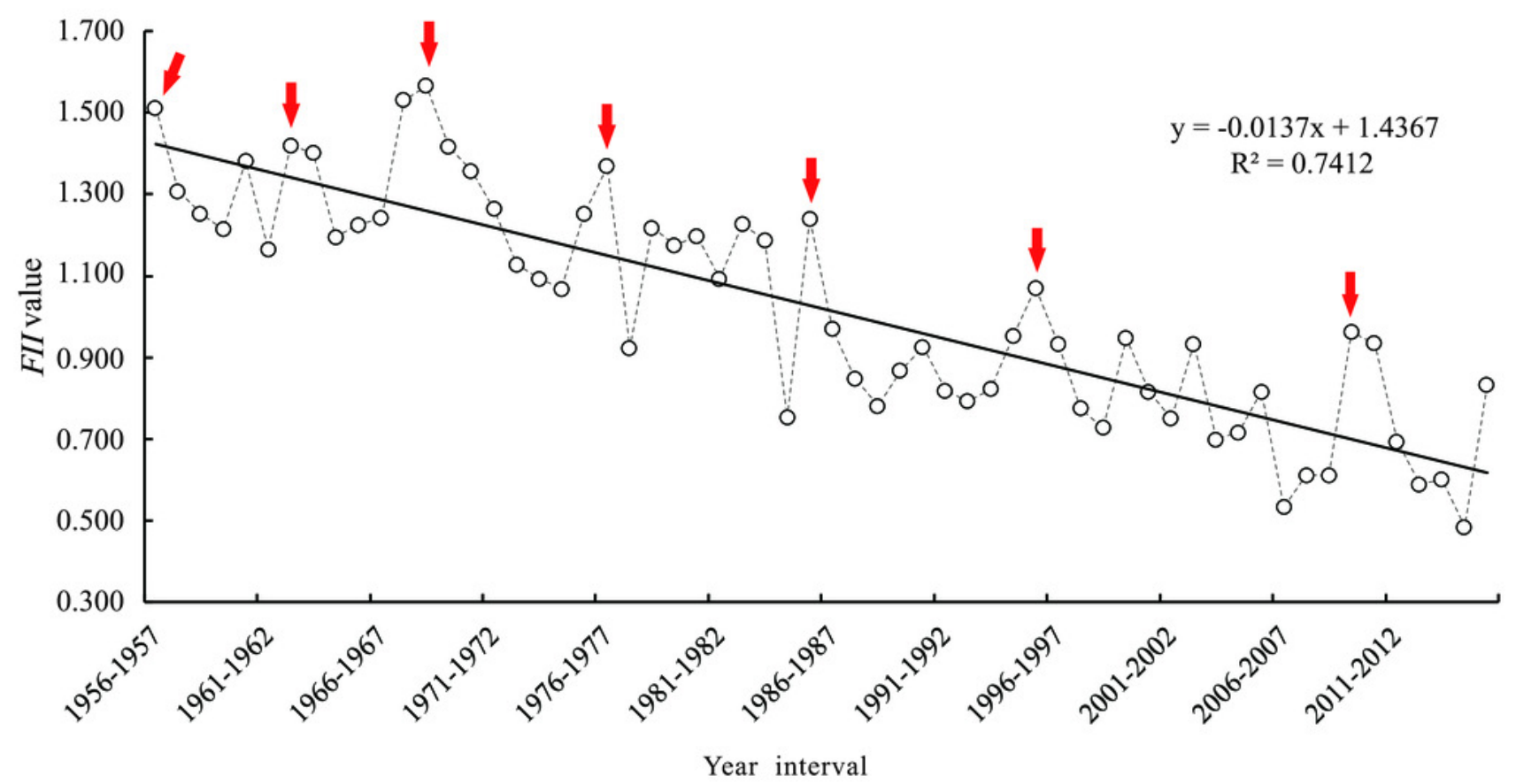


Figure 5

The residual histogram and P-P plot of the unary linear regression model.

(A) Residual histogram. (B) P-P plot.
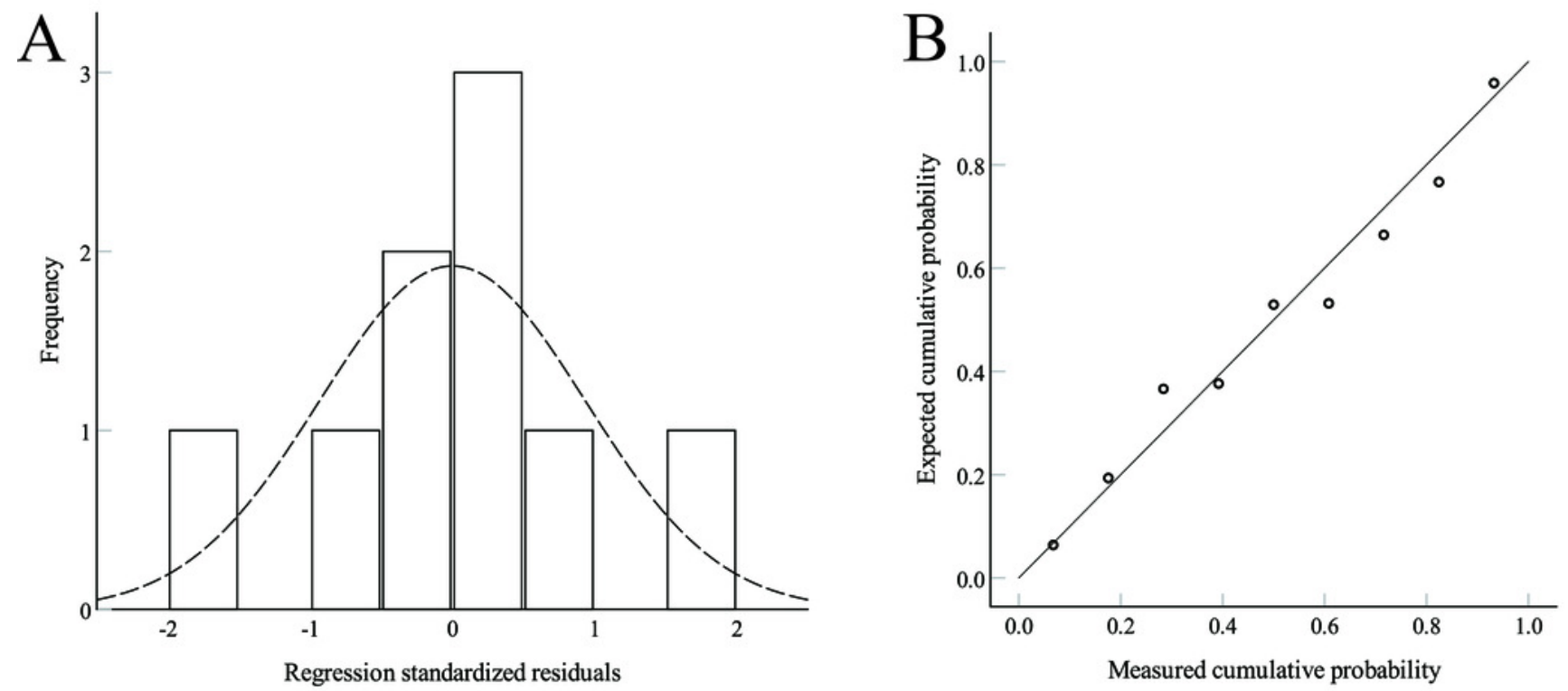
Figure 6

Changes in climate factors during the wintering period for the past 60 years.

(A) Duration of the overwintering period; (B) extreme minimum temperature during

overwintering periods; (C) average temperature during overwintering periods; (D) negatively accumulated temperature during overwintering periods.
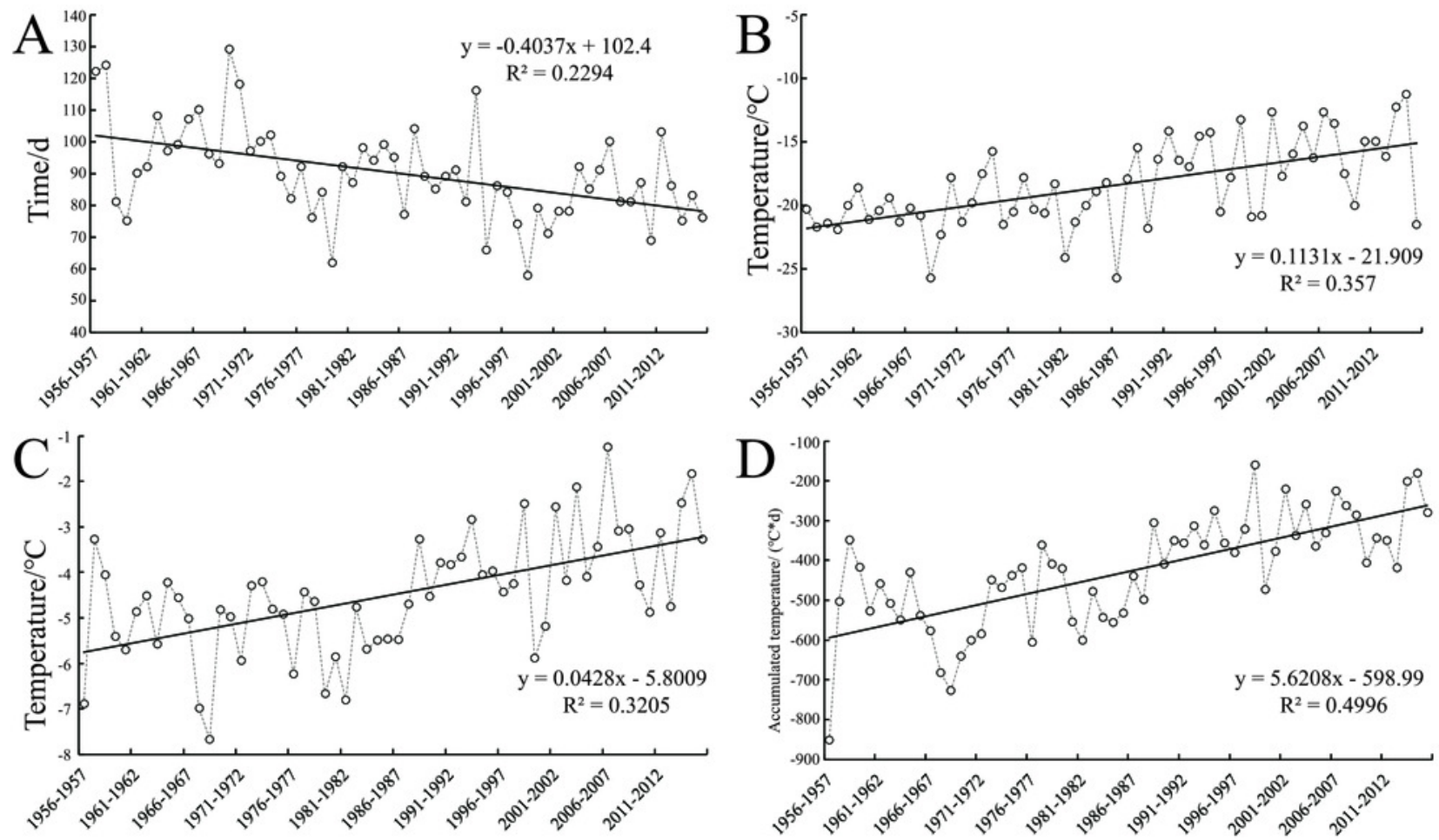


\section{Figure 7}

Results of $F /$ value changes in 60 years by Morlet wavelet analysis.

Morlet wavelet is used to transform the FIl value from 1956 to 2016, and the result of the wavelet analysis was drawn. (A) Wavelet coefficient real part graph. Abscissa, and ordinate represents the year and timescale (a), respectively. When the isoline is positive, it indicates that the degree of frost damage was serious. When the isoline is negative, it indicates that the degree of frost damage was light. The zero line indicates the turning point of the degree of frost damage. (B) Wavelet variance graph. The peak value indicates that the periodic oscillation is strong and the periodic characteristic is remarkable. (C) Periodic wavelet coefficient graph. The red curve represents the 33 a timescale, and the blue curve represents the 4 a timescale. 

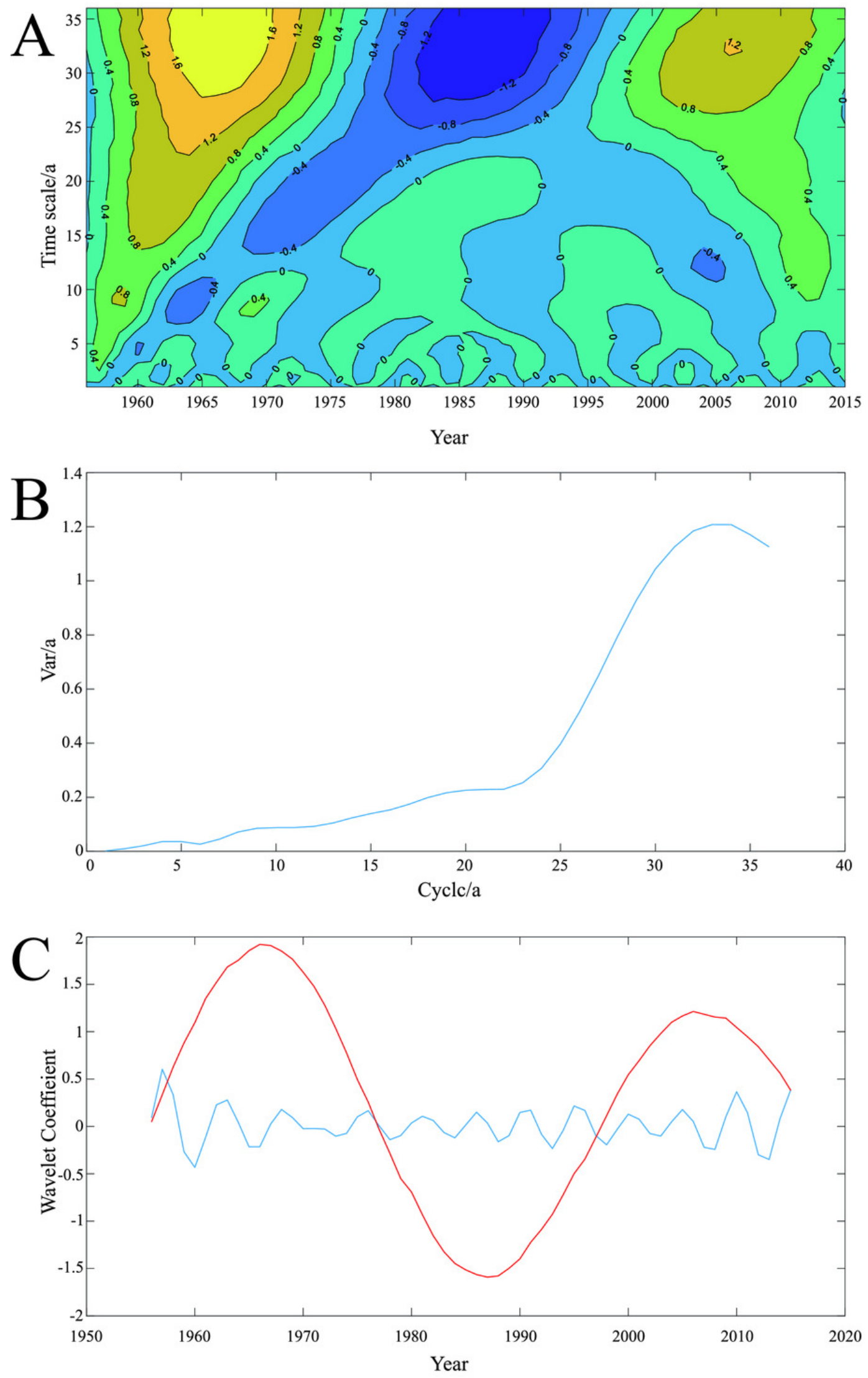


\section{Table $\mathbf{1}$ (on next page)}

Seven freezing disaster-causing factors and calculation methods 


\begin{tabular}{|c|c|c|}
\hline Code & Disaster-causing factors & Calculation method \\
\hline$x_{1}$ & Precipitation before overwintering & $\begin{array}{l}\text { The accumulated value of precipitation in } 25 \mathrm{~d} \\
\text { before overwintering }\end{array}$ \\
\hline$x_{2}$ & $\begin{array}{l}\text { Extreme minimum temperature in } \\
\text { the overwintering period }\end{array}$ & $\begin{array}{l}\text { The minimum of extreme minimum temperature } \\
\text { in the overwintering period }\end{array}$ \\
\hline$x_{3}$ & $\begin{array}{l}\text { Maximum-cooling range in the } \\
\text { overwintering period }\end{array}$ & $\begin{array}{l}\text { The maximum-cooling range of daily average } \\
\text { temperature in continuous } 72 \mathrm{~h} \text { during cooling } \\
\text { processes in the overwintering period }\end{array}$ \\
\hline$x_{4}$ & $\begin{array}{l}\text { Maximum daily temperature } \\
\text { difference in the overwintering } \\
\text { period }\end{array}$ & $\begin{array}{c}\text { Maximum daily temperature difference in the } \\
\text { overwintering period }\end{array}$ \\
\hline$x_{5}$ & $\begin{array}{l}\text { Negative accumulated temperature } \\
\text { in the overwintering period }\end{array}$ & $\begin{array}{c}\text { The cumulative value of daily mean temperature } \\
\text { less than } 0^{\circ} \mathrm{C} \text { in the overwintering period }\end{array}$ \\
\hline$x_{6}$ & $\begin{array}{l}\text { Average temperature in the } \\
\text { overwintering period }\end{array}$ & $\begin{array}{l}\text { Mean value of daily mean temperature in the } \\
\text { overwintering period }\end{array}$ \\
\hline$x_{7}$ & $\begin{array}{l}\text { Total precipitation in the } \\
\text { overwintering period }\end{array}$ & $\begin{array}{l}\text { Accumulated value of daily precipitation in the } \\
\text { overwintering period }\end{array}$ \\
\hline
\end{tabular}

1 